\title{
Cell cycle arrest and lytic induction of EBV-transformed B lymphoblastoid cells by a histone deacetylase inhibitor, Trichostatin A
}

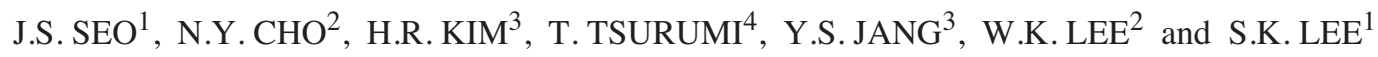 \\ ${ }^{1}$ Research Institute of Immunobiology, Catholic University, Seoul 137-701; ${ }^{2}$ Department of Biological Science \\ and Institute of Bioscience and Biotechnology, Myongji University, Yongin 449-728; ${ }^{3}$ Division of Biological Sciences, \\ Chonbuk National University, Chonju 561-756, Korea; ${ }^{4}$ Division of Virology, Aichi Cancer \\ Center Research Institute, Chikusa, Nagoya 464-8681, Japan
}

Received July 3, 2007; Accepted July 31, 2007

\begin{abstract}
Latent infection of the Epstein-Barr virus (EBV) is strongly associated with the pathogenesis of several human tumor types. The restricted expression of the latent EBV antigens is critical for EBV-associated tumors to escape from immune surveillance. EBV lytic replication can be triggered by various treatments and the induced lytic genes cause strong cytotoxic T lymphocyte (CTL) responses. Histone acetylation or deacetylation is associated with chromatin remodeling and regulates gene expression. Histone deacetylase (HDAC) inhibitors affect cell cycle progression as well as gene expression in a wide variety of transformed cells. We examined whether an HDAC inhibitor, TSA, can affect cell cycle progression and induce EBV lytic replication in EBV-transformed lymphoblastoid cell lines (LCLs). TSA caused cell cycle arrest at low concentrations and induced apoptosis at higher $(>300 \mathrm{nM})$ concentrations in the LCLs and EBV negative BJAB cells. To clarify the underlying mechanism of TSA-induced cell cycle arrest, expression of cell cycle regulatory factors was examined by RNase protection assay and Western blot analysis. Following TSA treatment, a reduced expression of cyclin D2 and an induction of p21 may have played an essential role for G1 arrest in LCLs, while p21 induction might have arrested BJAB cells in G1 phase. A Cdk inhibitor, p57, was increased by $300 \mathrm{nM}$ TSA in both LCLs and BJAB cells, indicating its role in apoptosis. Moreover, immunofluorescene assay and Western
\end{abstract}

Correspondence to: Dr Suk Kyeong Lee, Research Institute of Immunobiology, Catholic University of Korea, 505 Banpo-dong, Seocho-gu, Seoul 137-701, Korea

E-mail: sukklee@catholic.ac.kr

Key words: Epstein-Barr virus, histone deacetylase inhibitor, Tricostatin A, cell cycle, Epstein-Barr virus lytic replication blotting showed that TSA induced EBV lytic replication in LCL cells. These results suggest that TSA may exert an enhanced anti-tumor effect for EBV-associated tumors not only by inducing a cell cycle arrest and apoptosis, but also by triggering an EBV lytic cycle.

\section{Introduction}

Acetylation or deacetylation of histone changes the chromatin structure and regulates gene expression (1-3). An aberrant histone acetylation is linked to malignancies (4-6). Acetylation of the histone tail is catalyzed by a balanced action of two enzymes, histone acetyltransferase (HAT) and histone deacetylase (HDAC). A variety of small chemical agents, including Trichostatin A (TSA) and trapoxin, bind the catalytic domain of HDACs and block their activity in vitro and in vivo $(7,8)$. These HDAC inhibitors affect cell cycle progression and gene expression in a wide variety of transformed cells $(9,10)$, indicating they may be feasible anticancer agents.

Epstein-Barr virus (EBV), a ubiquitous human herpesvirus, is a causative agent of infectious mononucleosis. Latent EBV infection is also associated with several human malignancies of lymphoid and epithelial origins, including Hodgkin's disease, Burkitt's lymphoma, gastric carcinoma, nasopharyngeal carcinoma, and immunoblastic B-cell lymphoma in immunocompromised individuals (11-15). EBV lytic replication can be induced by various treatments, including anti-immunoglobulin (anti-IgG), phorbol esters (TPA), and butyrate (16-19). Zta (ZEBRA) protein, encoded by the BZLF1 gene, is an essential contributor to the initiation of a complete viral lytic cascade, ultimately leading to cell death $(20,21)$. Furthermore, cytotoxic $\mathrm{T}$ lymphocytes (CTLs) can recognize EBV latent and lytic antigens, resulting in effective removal of EBV infected cells (22-25). Thus, the induction of EBV lytic antigens could be a meaningful strategy for treatment of EBV-associated malignancies.

In this study, we examined whether the HDAC inhibitor TSA, can affect cell cycle progression and induce EBV lytic replication in tumor derived EBV-transformed lymphoblastoid cell lines (LCLs). 


\section{Materials and methods}

Cell culture and reagents. SNU-20 and SNU-1103 cells are B lymphoblastoid cell lines (LCLs) derived from cancer patients (26). SNU-1103 and SNU-20 harbor a type 1 and 2 EBV, respectively (27). BJAB is an EBV-negative Burkitt's lymphoma cell line. All cell lines were maintained in RPMI1640 medium supplemented with $10 \%$ heat-inactivated fetal bovine serum (Gibco BRL, San Diego, CA) and 10,000 $\mathrm{U} / \mathrm{ml}$ penicillin/streptomycin (Gibco BRL). Trichostatin A (TSA) was purchased from Sigma (Saint Louis, MO).

Cell growth analysis. Cells in the exponential growth phase were diluted to a density of $1.5 \times 10^{5}$ cells $/ \mathrm{ml}$ with fresh RPMI-1640 medium containing increasing concentrations of TSA or a vehicle $(0.0001 \%$ ethanol). The cells were cultured for 3 days in flat bottomed 96-well plates and counted every $24 \mathrm{~h}$ after staining with $0.4 \%$ trypan blue (Sigma).

Flow cytometric analysis of cell cycle. Cells were synchronized in RPMI-1640 medium supplemented with $0.5 \%$ FBS for $36 \mathrm{~h}$. Cells were then transferred into a medium containing $10 \%$ FBS and treated with TSA. The cells were harvested every $12 \mathrm{~h}$, washed with ice-cold phosphate-buffered saline (PBS), and fixed by dropwise addition of $70 \%$ ethanol. The fixed cells were stained with $50 \mu \mathrm{g} / \mathrm{ml}$ propidium iodide (PI, Sigma) solution containing DNase-free RNase 1 (500 U/ml). The cell cycle profile was assessed for 10,000 cells by flow cytometry using a FACS Calibur system (Becton-Dickinson, San Jose, CA) and the Cellquest analysis program (BectonDickinson).

RNase protection assay (RPA). Following treatment with TSA (100 and $300 \mathrm{nM}$ ) or a vehicle (marked as $0 \mathrm{nM}$ ) for $24 \mathrm{~h}$, cells were harvested and total RNA was isolated using an RNeasy Mini Kit (Qiagen, Hilden, Germany). RNA probes were prepared by in vitro transcription of the human cell cycle regulator multi-probe templates hCYC-1 (cyclins A, B, C, D1, D2, D3, and A1), hCC-2 (p53, p57, p27, p21, p19, p18, p16, and p14/15), and hCC-1 (Cdk 1, Cdk 2, Cdk 3, Cdk 4, p16, p21, and p16) (Pharmingen, San Diego, CA). Total cellular RNA was hybridized with ${ }^{32} \mathrm{P}$-labeled RNA probes at $56^{\circ} \mathrm{C}$ for $12-16 \mathrm{~h}$. Unprotected single-stranded RNA was removed by RNase $\mathrm{H}$ digestion and protected RNA duplex fragments precipitated and resolved in a 5\% denaturing polyacrylamide gel and analyzed by autoradiography.

Reverse transcription-polymerase chain reaction ( $R T-P C R)$ and Northern blot assay. Total RNA was purified using TRIzol reagent (Gibco BRL). cDNA was synthesized in a buffer (50 mM Tris-HCl, pH 8.3, $75 \mathrm{mM} \mathrm{KCl,} 3 \mathrm{mM} \mathrm{MgCl}_{2}$, $10 \mathrm{mM}$ DTT) containing SuperScript RNase H-reverse transcriptase (Gibco BRL), oligo(dT) primer, and $40 \mathrm{U}$ of RNase inhibitor. The following primers were used for PCR reaction: CDK2 (forward, 5'-GGAGAACTTCCAAAAGG TGG-3'; reverse, 5'-CTGGCTTGGTCACATCCTGG-3'). CDK4 (forward, 5'-TCTCGATATGAGCCAGTGGCTG-3'; reverse, 5'-TCCACGGGGCAGGGATACATC-3'), CDK6 (forward, 5'-ACTTGGATAAAGTTCCAGAGCCTGG-3'; reverse, 5'-TGGGAAGGGCAACATCTCTAG-3'), ß-actin (forward, 5'-ATCTGGCACCACACCTTCT-3'; reverse, 5'CGTCATACTCCTGCTTGCTG-3'), and GAPDH (forward, 5'-TGAAGGTCGGAGTCAACG-3'; reverse, 5'-CATGTGG GCCATGAGGTCCA-3'). Amplified PCR products were separated in a $1.5 \%$ agarose gel. For Northern blot analysis of p21 mRNA, $10 \mu \mathrm{g}$ of total RNA was separated in a $1.2 \%$ denaturing agarose gel and transferred to a nylon membrane. The blot was hybridized with a ${ }^{32} \mathrm{P}-$ labeled probe specific for p21. Hybridized bands were visualized by phospho-image analysis.

Western blot analysis. Cells cultured with TSA or a vehicle were lysed in a buffer $(20 \mathrm{mM}$ Tris- $\mathrm{HCl}, \mathrm{pH} 7.5,150 \mathrm{mM}$ $\mathrm{NaCl}, 0.1 \%$ SDS, $1 \%$ Triton $\mathrm{X}-100,1 \%$ sodium deoxycholate) containing $0.1 \mathrm{mM} \mathrm{NaF}, 0.02 \mathrm{mM}$ phenylmethylsulphonyl fluoride, $0.01 \mathrm{mM} \mathrm{Na}_{3} \mathrm{VO}_{4}, 0.1 \mu \mathrm{g} / \mathrm{ml}$ pepstatin, and $0.1 \mu \mathrm{g} / \mathrm{ml}$ leupeptin. Protein concentration was determined using the Bradford method. Equal amounts of protein (50 $\mu \mathrm{g}$ protein/ lane) were resolved in a $10 \%$ or $15 \%$ SDS-polyacrylamide gel and transferred to a nitrocellulose membrane. The blot was blocked with 5\% skim milk and then incubated with an appropriate primary antibody. Following incubation with an HRP-conjugated secondary antibody, protein bands were visualized using an ECL detection system (Amersham, Uppsala, Sweden). The primary antibodies for acetylated histone $\mathrm{H} 4$, poly (ADP ribose) polymerase (PARP), cyclin D1, cyclin D2, cyclin D3, cyclin E, p57, and B-actin, as well as the secondary antibodies were purchased from Santa Cruz Biotechnology, Inc. (Santa Cruz, CA). Expression of the EBV lytic gene was assessed using anti-BZLF1 (Dako, Glostrup, Denmark), anti-BRLF1 (Argene, Varilhes, France), anti-BMRF1 (Novocastra, Newcastle upon Tyne, UK), antiBALF5, and anti-BBLF2/3 antibodies (the last two antibodies were used in ref. 28).

Immunofluorescence assay (IFA). Cells were seeded on a 10 -well glass slide, fixed with $100 \%$ ice-cold methanol for 5 min, blocked with $20 \%$ normal goat serum (Jackson ImmunoResearch, West Grove, PA) for $20 \mathrm{~min}$, and washed with PBS. To detect expression of EBV lytic genes, antiBZLF1, anti-BMRF1, anti-gp110, and anti-gp350 (Chemicon, Temecula, CA) antibodies were used. Cy3-conjugated antimouse IgG (1:3000, Jackson ImmnoReasearch) was used as a secondary antibody.

\section{Results}

TSA treatment induced an acetylation of histone in LCLs and $B J A B$ cells. The effect of TSA on histone acetylation was examined in two EBV-transformed LCLs, SNU-20 and SNU-1103, and an EBV-negative B lymphoma cell line, $\mathrm{BJAB}$. Western blot analysis showed that levels of acetylated H4 histone increased in SNU-20 and SNU-1103 cells when the cells were incubated in the presence of 100 or $300 \mathrm{nM}$ TSA for $24 \mathrm{~h}$ (Fig. 1A). A time course experiment revealed that increased $\mathrm{H} 4$ acetylation was evident within $6 \mathrm{~h}$ of treatment with $100 \mathrm{nM}$ TSA in all three cell lines (Fig. 1B). Accumulation of hyperacetylated histone was also demonstrated by acid-urea-triton gel electrophoresis in TSA-treated SNU-20, SNU-1103 and BJAB cells (data not shown). 
(A)

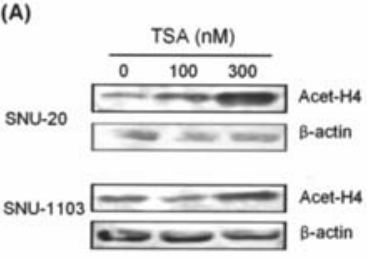

(B)

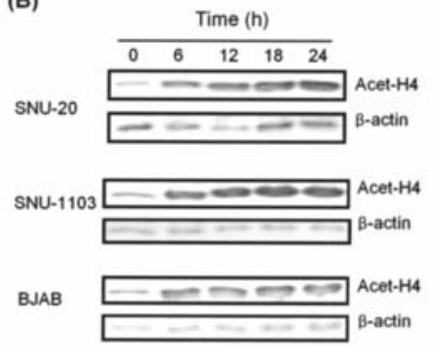

Figure 1. Effect of TSA on the histone acetylation. (A) Acetylated histone $\mathrm{H} 4$ (Acet-H4) was analyzed by Western blotting in cells incubated with increasing concentrations of TSA for $24 \mathrm{~h}$ or (B) with $100 \mathrm{nM}$ TSA for the indicated periods.
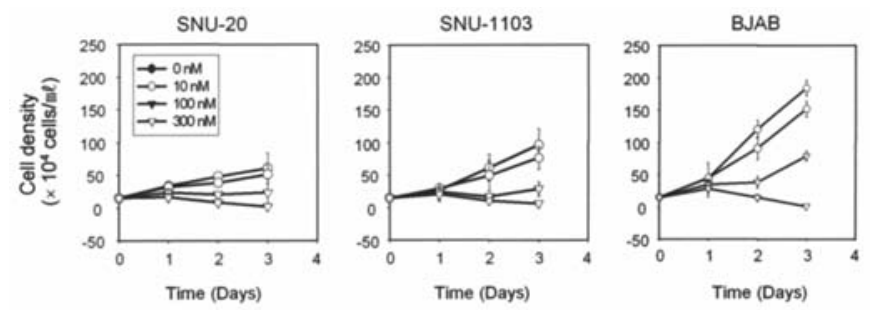

Figure 2. Effect of TSA on the growth of LCL and BJAB cells. Cells were seeded in 96-well plates and incubated with TSA. Viable and dead cells were counted after staining with trypan blue. Each value represents the mean \pm standard deviation obtained from triplicate samples.

TSA inhibited the growth of LCLs and BJAB cells. The effect of TSA on proliferation was examined in SNU-20, SNU-1103, and BJAB cells by the trypan blue exclusion method. A vehicle (DMSO) for TSA had no harmful effect on cell growth (data not shown). Addition of $10 \mathrm{nM}$ TSA to the medium caused only a marginal decrease in viable cells compared to the control (Fig. 2). However, all three cell lines showed little growth activity following $100 \mathrm{nM}$ TSA treatments. BJAB appeared to regain its growth ability slightly 3 days after the $100 \mathrm{nM}$ TSA treatment. A further increase of the TSA concentration to $300 \mathrm{nM}$ resulted in a complete loss of growth ability and gradual decrease of viability in all cell lines (Fig. 2).

TSA induced cell cycle arrest and PARP cleavage in LCLs and BJAB cells. To better understand how TSA might exert a growth inhibitory effect on B cells, flow cytometric analyses were carried out for TSA-treated or untreated cells after staining them with propidium iodide. In SNU-1103 cells, treatment of TSA for $24 \mathrm{~h}$ resulted in an increase of the cell population in $\mathrm{G} 1$ phase at $10 \mathrm{nM}$ and in $\mathrm{G} 2 / \mathrm{M}$ phase at $100 \mathrm{nM}$ (Fig. 3A). A further increase of TSA to $300 \mathrm{nM}$ caused an apparent disintegration of both G1- and G2/M-cell populations, resulting in a massive increase of the sub-G1 population. Incubation of BJAB cells with increasing concentrations of TSA also resulted in similar cell cycle arrests with SNU-1103 cells (Fig. 3B). In addition, TSA treatment at higher than $300 \mathrm{nM}$ concentration for $36 \mathrm{~h}$ caused an increase of the $85 \mathrm{kDa}$ PARP cleavage products with a corresponding decrease of the $116 \mathrm{kDa}$ intact PARP protein (Fig. 3C).

(A)
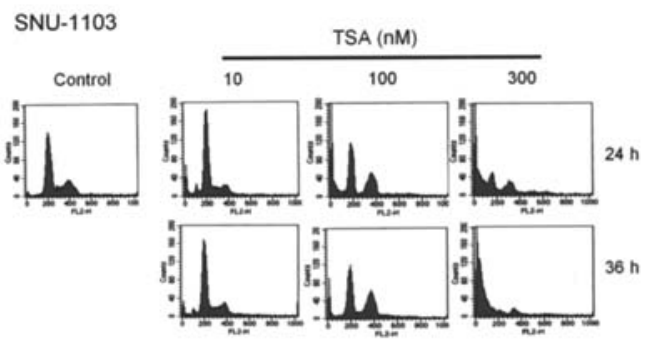

(B)

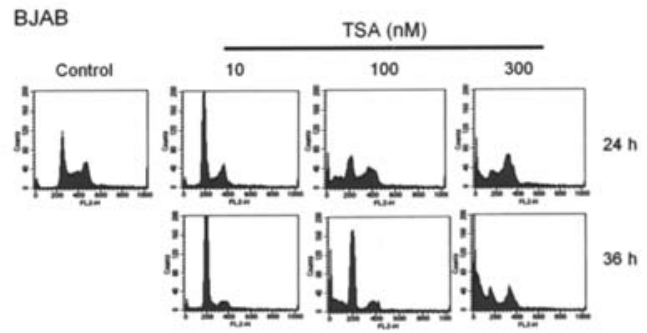

(C)

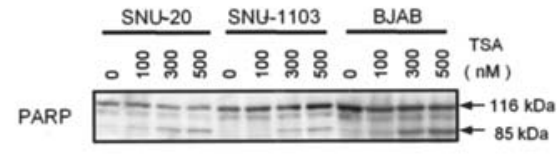

Figure 3. Effect of TSA on cell cycle arrest and PARP cleavage of LCLs and BJAB cells. SNU-1103 (A) and BJAB (B) cells were treated with TSA $(100$ and $300 \mathrm{nM})$ or a vehicle $(0 \mathrm{nM})$, harvested every $12 \mathrm{~h}$, fixed with $70 \%$ ethanol, and stained with PI for $30 \mathrm{~min}$ at $37^{\circ} \mathrm{C}$. DNA contents of the cells were assessed by flow cytometry and cell cycle distribution was analyzed using the Cellquest program. (C) For detection of PARP protein, cells were incubated with TSA for $36 \mathrm{~h}$ and the lysates analyzed by $15 \%$ SDS-PAGE followed by Western blot assay.

TSA affected the expression of cell cycle regulators. The effect of TSA on expression of cell cycle regulatory factors was analyzed by RPA. Under regular growth conditions, SNU-20 and SNU-1103 cells expressed a relatively high level of cyclin D2 mRNA and low level of cyclin D3, cyclin A, cyclin B, and cyclin C mRNA, but expressed little cyclin D1 and cyclin A1 mRNA (Fig. 4A). When the LCLs were exposed to TSA for $24 \mathrm{~h}$, the levels of the tested cyclin mRNA decreased simultaneously in a concentration-dependent manner. The mRNA of cyclin D2 decreased most dramatically among them. Untreated BJAB cells expressed mRNA for cyclin D3, cyclin A, cyclin B, and cyclin C, but poorly expressed cyclin D1, cyclin D2, and cyclin A1 mRNA. In $\mathrm{BJAB}$, the mRNA levels of cyclin D1 and cyclin D2 were slightly reduced by TSA treatment (Fig. 4A). A similar RPA analysis revealed that levels of Cdk1, Cdk2, and Cdk4 mRNA did not change after $24 \mathrm{~h}$ of TSA treatment in the three cell lines (data not shown). Additionally, RT-PCR analysis indicated little change in steady-state levels of Cdk2, Cdk4, and Cdk6 mRNA in SNU-20 and SNU-1103 cells following TSA treatment for $36 \mathrm{~h}$ (data not shown).

RPA analyses were also conducted to determine the effect of TSA on the expression of p53 tumor suppressor protein and various cyclin-dependent protein kinase inhibitors (CDKIs). In LCLs and BJAB cells, mRNAs for p53 and most of the CDKIs tested were expressed at easily detectable levels under regular growth conditions. In BJAB cells, mRNA levels 
(A)

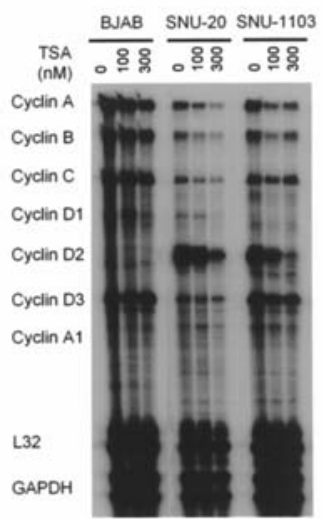

(C)

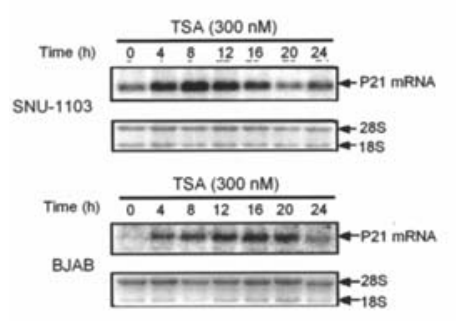

(D)
(B)
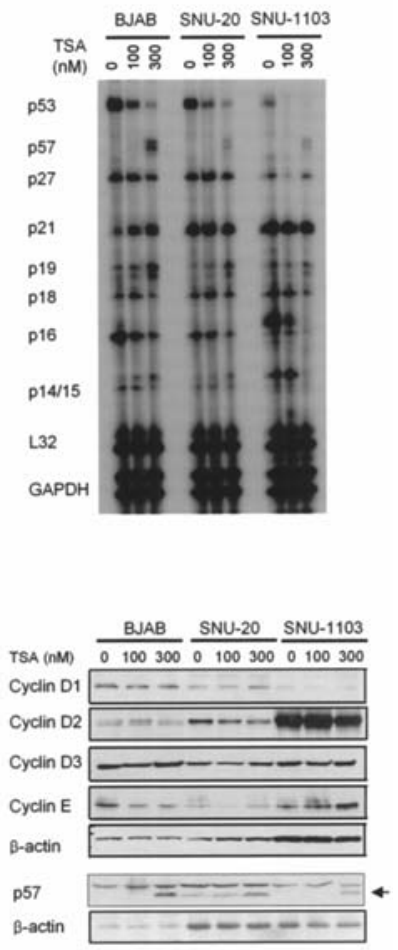

(A)

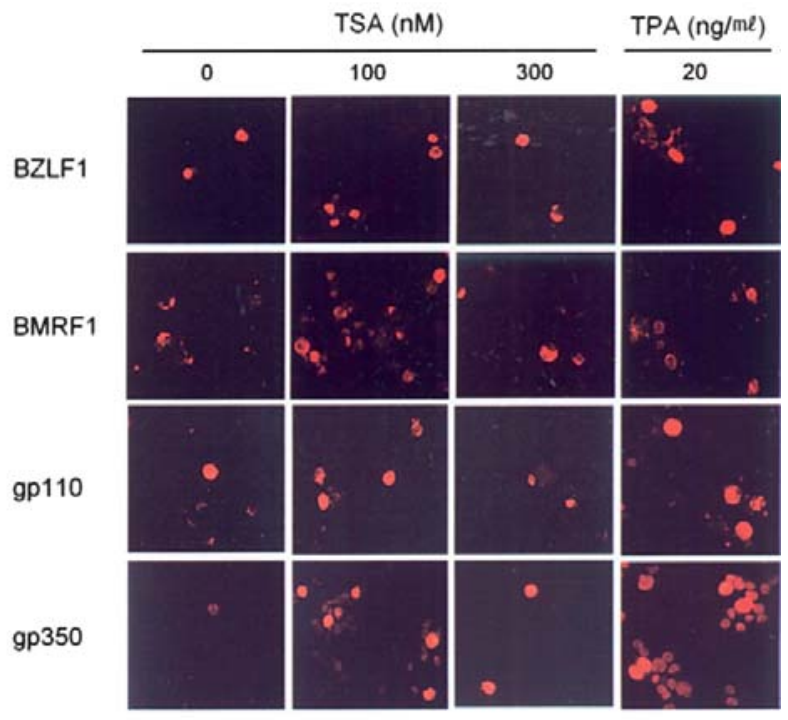

(B)

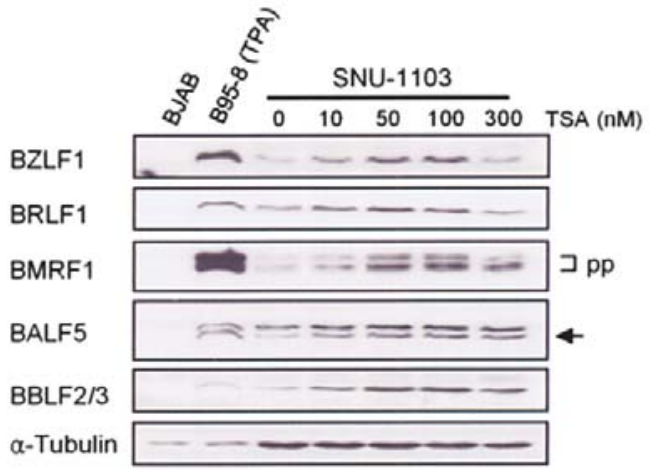

Figure 4. Effect of TSA on the expression of cell cycle regulatory genes. Cells were treated with TSA for $24 \mathrm{~h}$ and total RNA or total protein extracted from each sample. RPA was performed using the multi-probe template set hCYC-1 (A) or hCC-2 (B). Protected probes were separated in a $5 \%$ denaturing polyacrylamide gel and detected by autoradiography. (C) The mRNA expression of p21 was determined by Northern blot assay. (D) Western blotting was performed on total cell lysates (50 $\mu \mathrm{g}$ protein/lane) using appropriate antibodies (1:500).

for $\mathrm{p} 53, \mathrm{p} 16, \mathrm{p} 18$, and $\mathrm{p} 27$ decreased by $24 \mathrm{~h}$ following TSA treatment (Fig. 4B). LCLs showed similar gene expression patterns as BJAB cells following TSA treatment. Interestingly, the level of p21 mRNA sharply increased in BJAB but was unaffected in both LCLs after $24 \mathrm{~h}$ TSA treatment (Fig. 4B). Such a differential p21 mRNA accumulation may reflect different kinetics of p21 induction by TSA in these cells. To examine this possibility, Northern blot analysis to evaluate p21 mRNA levels in SNU-1103 and BJAB cells before and after $300 \mathrm{nM}$ TSA treatment at various time points was conducted (Fig. 4C). In SNU-1103, p21 mRNA increased within $4 \mathrm{~h}$, reached its peak (4-fold increase) at $8 \mathrm{~h}$, and then gradually diminished to the basal level by $20 \mathrm{~h}$ following TSA treatment. In BJAB, p21 mRNA was induced within $4 \mathrm{~h}$, accumulated to its maximum (17-fold increase) at $16 \mathrm{~h}$, and then slowly decreased, but still remained 9-fold higher than the basal level at $24 \mathrm{~h}$ following TSA treatment.

The effect of TSA on expression of the cell cycle regulatory proteins was also examined by Western blotting. The protein levels of cyclin D1 and cyclin D3 were unchanged in the three cell lines. In contrast, the levels of cyclin D2 were reduced with increasing concentrations of TSA in LCLs, unlike in $\mathrm{BJAB}$ where no change was detectable. Cyclin E expression increased slightly in SNU-20 and SNU-1103, while decreasing in $\mathrm{BJAB}$ following TSA treatment (Fig. 4D). Interestingly, increased mRNA and protein of $\mathrm{p} 57^{\mathrm{CIP} 2}$ were observed in all the tested B cell lines following treatment with $300 \mathrm{nM}$ TSA but not with $100 \mathrm{nM}$ TSA (Fig. 4B and D).

Figure 5. Effect of TSA on expression of EBV lytic genes. (A) SNU-1103 cells were treated with TSA (100 or $300 \mathrm{nM}$ ) for $48 \mathrm{~h}$. Negative control cells were treated with a vehicle, while positive control cells were treated with TPA $(20 \mathrm{ng} / \mathrm{ml})$ for $48 \mathrm{~h}$ to induce the EBV lytic cycle. As a primary antibody, BZLF1 (1:40), EA-D (1:500), gp110 (1:1000), or gp350 (1:1000) specific antibody was used. Cy3-cojugated anti-mouse monoclonal antibody or $\mathrm{Cy}-3$ conjugated anti-rabbit polyclonal antibody was used as a secondary antibody. (B) Cells were treated with TSA for $48 \mathrm{~h}$ and Western blotting was performed on the total cell lysates ( $50 \mu \mathrm{g}$ protein/lane) using indicated antibodies. All results shown were obtained from a single membrane by repeatedly stripping it for each antibody reaction. pp, phosphorylated form of BMRF1. The arrow indicates an expected BALF5 protein band.

TSA induced the expression of EBV lytic genes. The effect of TSA on the expression of EBV lytic genes was determined by immunofluorescene assay. While treatment with $100 \mathrm{nM}$ TSA for $24 \mathrm{~h}$ had little effect on the expression of EBV lytic genes (data not shown), treatment with $100 \mathrm{nM}$ TSA for $48 \mathrm{~h}$ induced expression of EBV early genes (BZLF1 and BMRF1) and late genes (gp110 and gp350) in SNU-1103 cells (Fig. 5A). Lytic induction was also observed in cells treated with $50 \mathrm{nM}$ TSA (data not shown). The effect of $300 \mathrm{nM}$ TSA on lytic induction seemed to be counter-balanced by increased cell death (Fig. 5A). Similar results were obtained from SNU-20 cells (data not shown). The effect of TSA on the induction of EBV lytic genes was confirmed by Western blot analysis, and expression of BZLF1, BRLF1, BMRF1, BALF5, and $\mathrm{BBLF} 2 / 3$ proteins increased in a concentration-dependent manner following TSA treatment (Fig. 5B). Similar to that 
observed in Fig. 5A, 300 nM TSA was not more effective than $100 \mathrm{nM}$ TSA in inducing lytic gene expression (Fig. 5B).

\section{Discussion}

TSA had a cytostatic effect at $10-100 \mathrm{nM}$ and cytotoxic effect at greater than $300 \mathrm{nM}$ for both EBV infected LCLs and EBV uninfected BJAB cells. We observed that, unlike LCLs, BJAB cells recover cell growth 2 days after $100 \mathrm{nM}$ TSA treatment. The cytostatic effect of low level TSA may be overcome in BJAB after a certain period either because BJAB exerts a higher growth rate than LCLs or because the cells can degrade TSA more efficiently than LCLs. The results of cell cycle analyses indicate that TSA inhibits cell growth of LCLs and BJAB by inducing G1 and G2/M arrest as well as by causing apoptosis.

In LCLs and BJAB, the expression levels of mRNA and protein for cyclin D family members were maintained differentially in an unstimulated state and regulated differentially following TSA stimulation. Our results showed that TSA selectively down-regulated cyclin D1 and D2 in BJAB among the cyclin D family members. However, TSA inhibited expression of all the cyclin proteins, especially cyclin D2, in LCL cells. The high level cyclin D2 expression observed in LCLs may be related to EBNA-2 and EBNA-LP expression in latency III infected B cells. These EBV latent proteins are known to induce cyclin D2 expression (29). The p21 Waf1/Cip1 is a target gene of p53 and commonly induced by a variety of HDAC inhibitors, including TSA. The induced expression of $\mathrm{p} 21^{\text {Waf } 1 / \mathrm{Cip} 1}$ constitutes a major driving force leading to a blockage of the cell growth in several transformed cell types (30). We found that TSA treatment decreased the p53 mRNA level in a dose-dependent manner, while increasing the p21 mRNA level. Thus, TSA induced p21 expression seems to be independent of p53 in our system. The cell cycle arrest induced by TSA is most likely mediated by rapid induction of $\mathrm{p} 21$ followed by reduced expression of cyclin D2 in LCLs. In contrast, induction of p21 might have played an essential role for $\mathrm{G} 1$ arrest in BJAB cells.

The expression of mRNA and protein of $\mathrm{p} 57^{\mathrm{Kip} 2}$, another Cdk inhibitor, was significantly increased by $300 \mathrm{nM}$ TSA in all the three $B$ cell lines. A transcriptional activation of p57 by HDAC inhibitors was also reported in other types of cells (31). TSA induced expression of $\mathrm{p} 57^{\mathrm{Kip} 2}$ may have caused apoptosis rather than cell cycle arrest in our study because $300 \mathrm{nM}$ TSA induced massive cell death. p57 Kip2 was shown to cause a stimulated apoptosis in HeLa cells (32).

EBV latency is strongly associated with several malignancies. A potential therapeutic strategy for these tumors involves induction of the EBV lytic cycle causing cell death and immune attack $(33,34)$. In EBV infected cell lines, usually a small subpopulation of cells shows spontaneous induction of the lytic cycle. Although the mechanism of switching is not clearly understood, EBV lytic replication can be started by activation of the immediate early genes, BZLF1 and BRLF1 (35-37). It has been suggested that histone acetylation of the Zp promoter can reactivate EBV through transcription of BZLF1 (38). We observed that TSA induced reactivation of EBV lytic cycle in SNU-1103 and SNU-20 cell lines. TSA may have induced EBV lytic cycle via modifying the Zta promoter. Under our experimental condition, TSA induced lytic cycle after 48 -h treatment but not after $24 \mathrm{~h}$ treatment, which is a similar to that observed using phorbol ester to induce a lytic cycle. It should be noted that $100 \mathrm{nM}$ TSA caused continuous cell growth inhibition for 3 days in LCLs while BJAB cells began to regrow 2 days after TSA treatment. This discrepancy may be caused by the TSA-induced EBV lytic cycle in LCLs resulting in cell death.

In this study, we demonstrated that TSA not only caused cell cycle arrest and apoptosis but also effectively induced EBV lytic replication in EBV transformed B cells. Therefore, HDAC inhibitors may exert an additive anticancer activity for EBV-associated tumors. Further experiments are necessary to determine the acetylation state of the $\mathrm{Zp}$ promoter and susceptibility of EBV-associated tumor cells to cytotoxic T cell (CTL) attack following HDAC inhibitor treatment.

\section{Acknowledgments}

This work was supported by grant No. R01-1999-000-00066-0 from the Basic Research Program of the Science \& Engineering Foundation. J.S. Seo was supported by the Seoul Science Fellowship.

\section{References}

1. Van Lint C, Emiliani S and Verdin E: The expression of a small fraction of cellular genes is changed in response to histone hyperacetylation. Gene Expr 5: 245-253, 1996.

2. Kuo MH and Allis CD: Roles of histone acetyltransferases and deacetylases in gene regulation. Bioessays 20: 615-626, 1998.

3. Gregory PD, Wagner K and Horz W: Histone acetylation and chromatin remodeling. Exp Cell Res 265: 195-202, 2001.

4. Struhl K: Histone acetylation and transcriptional regulatory mechanisms. Genes Dev 12: 599-606, 1998.

5. Wang C, Fu M, Mani S, Wadler S, Senderowicz AM and Pestell RG: Histone acetylation and the cell-cycle in cancer. Front Biosci 6: D610-D629, 2001.

6. Minucci S and Pelicci PG: Histone deacetylase inhibitors and the promise of epigenetic (and more) treatments for cancer. Nat Rev Cancer 6: 38-51, 2006.

7. Grunstein M: Histone acetylation in chromatin structure and transcription. Nature 389: 349-352, 1997.

8. Konstantinopoulos PA and Papavassiliou AG: Chromatinmodulating agents as epigenetic anticancer drugs - 'the die is cast'. Drug Discov Today 11: 91-93, 2006.

9. Marks PA, Richon VM and Rifkind RA: Histone deacetylase inhibitors: inducers of differentiation or apoptosis of transformed cells. J Natl Cancer Inst 92: 1210-1216, 2000.

10. Kim MS, Blake M, Baek JH, Kohlhagen G, Pommier Y and Carrier F: Inhibition of histone deacetylase increases cytotoxicity to anticancer drugs targeting DNA. Cancer Res 63: 7291-7300, 2003

11. Klein G: Role of EBV and Ig/myc translocation in Burkitt lymphoma. Antibiot Chemother 46: 110-116, 1994

12. Chapman AL and Rickinson AB: Epstein-Barr virus in Hodgkin's disease. Ann Oncol 9 (Suppl. 5): S5-S16, 1998.

13. Rickinson AB: Epstein-Barr virus. Virus Res 82: 109-113, 2002.

14. Friedrich RE, Bartel-Friedrich S, Lobeck, H, Niedobitek G and Arps H: Epstein-Barr virus DNA and epithelial markers in nasopharyngeal carcinoma. Med Microbiol Immunol 192: 141$144,2003$.

15. Young LS and Murray PG: Epstein-Barr virus and oncogenesis: from latent genes to tumours. Oncogene 22: 5108-5121, 2003.

16. Takase K, Kelleher CA, Terada N, Jones JF, Lucas JJ and Gelfand EW: Dissociation of EBV genome replication and host cell proliferation in anti-IgG-stimulated Akata cells. Clin Immunol Immunopathol 81: 168-174, 1996.

17. Flemington E and Speck SH: Identification of phorbol ester response elements in the promoter of Epstein-Barr virus putative lytic switch gene BZLF1. J Virol 64: 1217-1226, 1990. 
18. Baumann M, Mischak H, Dammeier S, et al: Activation of the Epstein-Barr virus transcription factor BZLF1 by 12-Otetradecanoylphorbol-13-acetate-induced phosphorylation. J Virol 72: 8105-8114, 1998.

19. Gradoville L, Kwa D, El-Guindy A and Miller G: Protein kinase C-independent activation of the Epstein-Barr virus lytic cycle. J Virol 76: 5612-5626, 2002.

20. Countryman J, Jenson H, Seibl R, Wolf H and Miller G: Polymorphic proteins encoded within BZLF1 of defective and standard Epstein-Barr viruses disrupt latency. J Virol 61: 3672-3679, 1987.

21. Feederle R, Kost M, Baumann M, Janz A, Drouet E, Hammerschmidt W and Delecluse HJ: The Epstein-Barr virus lytic program is controlled by the co-operative functions of two transactivators. EMBO J 19: 3080-3089, 2000.

22. Rickinson AB: Immune intervention against virus-associated human cancers. Ann Oncol 6 (Suppl. 1): 69-71, 1995.

23. Chapman AL, Rickinson AB, Thomas WA, Jarrett RF, Crocker J and Lee SP: Epstein-Barr virus-specific cytotoxic T lymphocyte responses in the blood and tumor site of Hodgkin's disease patients: implications for a T-cell-based therapy. Cancer Res 61: 6219-6226, 2001.

24. Bollard CM, Aguilar L and Straathof KC: Cytotoxic T lymphocyte therapy for Epstein-Barr virus ${ }^{+}$Hodgkin's disease. J Exp Med 200: 1623-1633, 2004.

25. Fogg MH, Garry D, Awad A, Wang F and Kaur A: The BZLF1 homolog of an Epstein-Barr-related gamma-herpesvirus is a frequent target of the CTL response in persistently infected rhesus macaques. J Immunol 176: 3391-3401, 2006.

26. Park JG, Lee JH, Kang MS, et al: Characterization of cell lines established from human hepatocellular carcinoma. Int $\mathrm{J}$ Cancer 62: 276-282, 1995.

27. Lee WK, Kim SM, Sim YS, Cho SG, et al: B-Lympho-blastoid cell lines from cancer patients. In Vitro Cell Dev Biol 34: 97-101, 1998.

28. Daikoku T, Kudoh A, Fujita M, Sugaya Y, Isomura H, Shirata N and Tsurumi T: Architecture of replication compartment formed during Epstein-Barr virus lytic repliation. J Virol 79: 3409-3418, 2005 .
29. Pokrovskaja K, Ehlin-Henriksson B, Bartkova J, et al: Phenotype-related differences in the expression of D-type cyclins in human B cell-derived lines. Cell Growth Differ 7: 1723-1732, 1996.

30. Chen WJ, Chang CY and Lin JK: Induction of G1 phase arrest in MCF human breast cancer cells by pentagalloylglucose through the down-regulation of CDK4 and CDK2 activities and up-regulation of the CDK inhibitors p27(Kip) and p21(Cip). Biochem Pharmacol 65: 1777-1785, 2003.

31. Shin JY, Kim HS, Park J, Park JB and Lee JY: Mechanism for inactivation of the KIP family cyclin-dependent kinase inhibitor genes in gastric cancer cells. Cancer Res 60: 262-265, 2000.

32. Samuelsson MK, Pazirandeh A and Okret S: A pro-apoptotic effect of the CDK inhibitor p57(Kip2) on staurosporine-induced apoptosis in HeLa cells. Biochem Biophys Res Commun 296: 702-709, 2002.

33. Feng WH, Cohen JI, Fischer S, et al: Reactivation of latent Epstein-Barr virus by methotrexate: a potential contributor to methotrexate-associated lymphomas. J Natl Cancer Inst 96: $1691-1702,2004$

34. Wang $\mathrm{H}$ and Cao Y: BZLF1 controlled by family repeat domain induces lytic cytotoxicity in Epstein-Barr virus-positive tumor cells. Anticancer Res 24: 67-74, 2004.

35. Countryman J and Miller G: Activation of expression of latent Epstein-Barr herpesvirus after gene transfer with a small cloned subfragment of heterogeneous viral DNA. Proc Natl Acad Sci USA 82: 4085-4089, 1985.

36. Hardwick JM, Lieberman PM and Hayward SD: A new EpsteinBarr virus transactivator, $\mathrm{R}$, induces expression of a cytoplasmic early antigen. J Virol 62: 2274-2284, 1988.

37. Ragoczy T, Heston L and Miller G: The Epstein-Barr virus Rta protein activates lytic cycle genes and can disrupt latency in B lymphocytes. J Virol 72: 7978-7984, 1998.

38. Jenkins PJ, Binne UK and Farrell PJ: Histone acetylation and reactivation of Epstein-Barr virus from latency. J Virol 74 : 710-720, 2000. 